\title{
PENGARUH DIMENSI COMPUTER SELF EFFICACY (CSE) TERHADAP PRESTASI AKADEMIK MAHASISWA
}

\author{
Muhammad Bunyamin ${ }^{1}$, Siti Sauda ${ }^{2}$ \\ Fakultas Ilmu Komputer \\ Universitas Bina Darma \\ email : muhammad.bunyamin@binadarma.ac.id ${ }^{1}$, siti_sauda@binadarma.ac.id ${ }^{2}$ \\ Jl. A. Yani No. 12, Palembang 30624, Indonesia
}

\begin{abstract}
Abstrak
Penilaian kapabilitas atau kemampuan seseorang dalam pemanfaatan teknologi informasi merupakan konsep dasar dari Computer Self Efficacy (CSE). CSE juga merupakan bagian dari prediktor yang penting bagi mahasiswa untuk mempelajari dan menggunakan sistem komputer. CSE mempunyai tiga dimensi yaitu Computer Based Skills, Media Reated Skills, dan Web Based Skills. Dengan demikian dapat dikatakan CSE dapat mempengaruhi prestasi akademik mahasiswa yang mempelajari sistem komputer (mahasasiswa ilmu komputer). Dengan pedekatan Structural Equation Modeling, penelitian ini menunjukkan, yang memiliki pengaruh positif dan signifikan terhadap prestasi akademik mahasiswa adalah Computer Based Skills dan Web Based Skills, akan tetapi Media Reated Skills tidak mempengaruhi prestasi akademik mahasiswa.

Kata kunci : Computer Self Efficacy, Prestasi Akademik Mahasiswa, Structural Equation Modeling
\end{abstract}

\section{PENDAHULUAN}

Untuk mendukung Visi Universitas Bina Darma yaitu "Menjadi Universitas Berstandar Internasional Berbasis Teknologi Informasi Pada Tahun 2025", semua kegiatan akademik seperti, peneriamaan mahasiswa baru, pembayaran biaya kuliah, pengentrian mata kuliah, pengumuman hasil kuliah, sampai proses pengajuan judul proposal dan skripsi pun telah di dasari oleh sebuah sistem informasi yang dapat di akses secara online melalui sisfo.binadarma.ac.id. Bukan hanya itu, kegiatan pembelajaran pun sudah di dukung dengan modul pembelajaran jarak jauh seperti e-learning dan pembelajaran melalui video conference. Sebagai alat untuk penyampaian informasi Universitas Bina Darma juga memiliki website baik pada tingkat universitas, fakultas, program studi, sampai ke blog masing masing dosen. Ada juga sistem yang masih dalam tahap pengembangan yaitu sistem absensi mahasiswa dengan menggunakan smart card pada tiap kelas. Hal ini dilakukan untuk meningkatkan kualitas belajar mengajar dan dengan penggunaan teknologi informasi diharapkan akan meningkatkan 
prestasi akademik mahasiswa.

Penilaian terhadap kemampuan dalam pemanfaatan teknologi ingormasi merupakan konsep dasari dari Computer Self Efficacy. Dalam penugasan bidang teknologi informasi, CSE merupakan salah satu variabel yang penting untuk mengamati studi prilaku individual (Agarwal, Sambamurthy et al. 2000). Studi tentang CSE ini penting dalam rangka menentuka kinerja dan perilaku indvidu dalam penggunaan teknologi informasi/komputer. (Compeau and Higgins 1995). Computer Self Efficacy adalah sebuah konstruksi multidimensi yang didasari oleh tiga dimensi yaitu Basic Computer Skills (Keterampilan dasar komputer), Media Related Skills (Keterampilan yang terkait dengan media), dan Web Based Skills (Keterampilan Berbasis Web) (Teo and Hwee Ling Koh, 2010). Dalam mempelajari dan menggunakan teknologi informasi, CSE juga merupakan salah satu prediktor yang penting (Rustina, 2004).

Beberapa penelitian telah membuktikan Self Efficacy berpengaruh positif terhadap prestasi akademik (Warsito, 2012, Handayani, 2013, Adiputra, 2015). Dengan demikian untuk mahasiswa yang mempelajari tentang teknologi informasi (mahasiswa ilmu komputer), dapat di indikasi bahwa self efficacy dalam penggunaan teknologi informasi (Computer Self Efficacy) juga memiliki peranan penting dalam pencapaian prestasi akademik mahasiswa.

Berdasarkan hal-hal yang telah di uraikan di atas, perlu adanya penelitian tentang bagaimana pengaruh dimensi dimensi Computer Self Efficacy terhadap prestasi mahasiswa bidang ilmu komputer di lingkungan Universitas Bina Darma. Oleh karena itu dengan dasar dari uraian tersebut diambil sebuah penelitian yang berjudul "Pengaruh Dimensi Computer Self Efficacy (CSE) Terhadap Prestasi Akademik Mahasiswa".

Pada penelitian ini penulis hanya berfokus kepada mencari bukti empriris pengaruh dimensi-dimensi Computer self Efficacy terhadap prestasi akademik mahasiswa dikalangan mahasiswa ilmu komputer Universitas Bina Darma Palembang.

\section{METODOLOGI PENELITAN}

\subsection{Desain Penelitian}

Pada penelitian ini, penulis menggunakan Structural Equation Models untuk menganalisa atau mengukur pengaruh dimensi-dimensi Computer Self Efficacy terhadap prestasi akademik mahasiswa bidang ilm komputer di Universitas Bina Darma Palembang

\subsection{Teknik Pengumpulan Data}

Penelitian ini menggunakan dua jenis data yaitu data primer dan sekunder. Data primer didapat dengan cara menyebarkan kuisioner melalui sistem informasi akademik yang dipakai mahasiswa, kuisioner berisi tentang ketiga dimensi CSE, sedangkan untuk prestasi akademik didapat dari IPK yang terdapat di dalam Sistem Informasi Akademik. Data sekunder didapat dari berbagai referensi yang relevan dengan penelitian seperti sejarah Universitas Bina Darma, struktur dan bagian organisasi.

\subsection{Definisi Oprasional Variabel}

Variabel yang berkaitan dalam penelitian ini dapat di jelaskan dalam tabel 1 berikut. 
Tabel 1: Definisi Oprasional Variabel

\begin{tabular}{|c|c|c|c|}
\hline No & Variabel & Definisi & Referensi \\
\hline 1 & $\begin{array}{l}\text { Basic Computer } \\
\text { Skills }(B S C)\end{array}$ & $\begin{array}{l}\text { Merupakan salah satu dimensi Computer Self } \\
\text { Efficacy yang mendefinisikan tentang } \\
\text { kemampuan dasar penggunaan komputer. }\end{array}$ & $\begin{array}{l}\text { Teo and Hwee } \\
\text { Ling Koh (2010) }\end{array}$ \\
\hline 2 & $\begin{array}{l}\text { Media Related } \\
\text { Skills (MRS) }\end{array}$ & $\begin{array}{l}\text { Salah satu dimensi CSE yang mendefinisikan } \\
\text { tentang kemampuan penggunaan komputer } \\
\text { dalam bidang multimedia }\end{array}$ & $\begin{array}{l}\text { Teo and Hwee } \\
\text { Ling Koh (2010) }\end{array}$ \\
\hline 3 & $\begin{array}{l}\text { Web Based Skills } \\
(W B S)\end{array}$ & $\begin{array}{l}\text { Salah satu dimensi CSE yang mendefinisikan } \\
\text { tentang kemampuan penggunaan komputer yang } \\
\text { berbasis web }\end{array}$ & $\begin{array}{l}\text { Teo and Hwee } \\
\text { Ling Koh (2010) }\end{array}$ \\
\hline 4 & $\begin{array}{l}\text { Prestasi Akademik } \\
\text { Mahasiswa }\end{array}$ & $\begin{array}{l}\text { Hasil yang dicapai seorang mahasiswa dalam } \\
\text { bidang akademisnya }\end{array}$ & $\begin{array}{l}\text { Chaplin (2006), } \\
\text { Djamarah (2002) }\end{array}$ \\
\hline
\end{tabular}

\subsection{Teknik Analisis Data}

Pemilihan teknik analisis data yang digunakan dalam penelitian ini adalah model persamaan structural (Structural Equation Model). Model ini dipilih dengan cara memperhatikan kerangka teoritis, model penelitian, dan tahapan penelitian yang telah dirumuskan sebelumnya. Pada prinsipnya model persamaan struktural ini merupakan analisis yang menggambarkan penerapan dari beberapa model secara kompak (Ferdinand, 2002).

Besarnya sampel dalam penelitian ini disesuaikan dengan Structural Equation Model (SEM) yang merupakan model analisis yang digunakan. Berkaitan dengan hal tersebut, ukuran sampel untuk SEM yang menggunakan Maximum Likelihood Estimation (MLE) adalah sebanyak 5 - 10 kali dari jumlah variabel yang diestimasi yaitu 100-200 sampel. Dapat disimpulkan, jumlah responden yang harus dikumpulkan dalam penelitian ini paling tidak 200 responden.

Terdapat tujuh langkah yang harus ditempuh, dalam pengujian model dengan menggunakan Structural Equation Modelling (SEM) (Hair, et al, 2010; dan Ferdinand, 2002 ). Langkah-langkah tersebut adalah sebagai berikut:

1) pengembangan Model Berbasis Teori,

2) pengembangan Diagram Jalur (Path Diagram),

3) konversi diagram jalur ke dalam persamaan struktural dan model pengukuran,

4) memilih matriks input dan estimasi model,

5) penilaian Problem Identifikasi,

6) pengujian Goodness of Fit Index,

7) interpretasi dan modifikasi model;

\subsection{Hipotesis Penelitian}

Hipotesis penelitian dapat ditentukan sebagai berikut:

H1 : Basic Computer Skills berpengaruh positif terhadap prestasi akademik.

$\mathrm{H} 2$ : Media Related Skills berpengaruh positif terhadap prestasi akademik.

H3 : Web Based Skills berpengaruh positif terhadap prestasi akademik.

\section{HASIL DAN PEMBAHASAN}

\subsection{Data Penelitian}

Untuk keperluan akurasi data, maka data dikumpulkan melalui sistem akademik yang dipakai mahasiswa (sisfo.binadarma.ac.id). Kuisioner ditujukan kepada responden mahasiswa Ilmu Komputer. Hasil pengumpulan data didapat 333 data kuisioner yang di isi mahasiswa. Dalam penelitian ini yang menjadi respoanden adalah mahasiswa bidang Ilmu Komputer yang tercatat sebagai mahasiswa aktif di Universitas Bina Darma. 
Hair (2014) menyarankan sebelum melakukan proses analisis data, data harus dipersiapkan dengan pemeriksaan asumsi yang melandasi Structural Equation Modeling (SEM) adalah meliputi missing value, unengaged respon, uji outlier, normalitas, linieritas, validitas dan reabilitas.

\subsection{Hasil Analisis Data}

Pengolahan dari tahap awal full model SEM disajikan pada gambar 1 sebagai berikut.

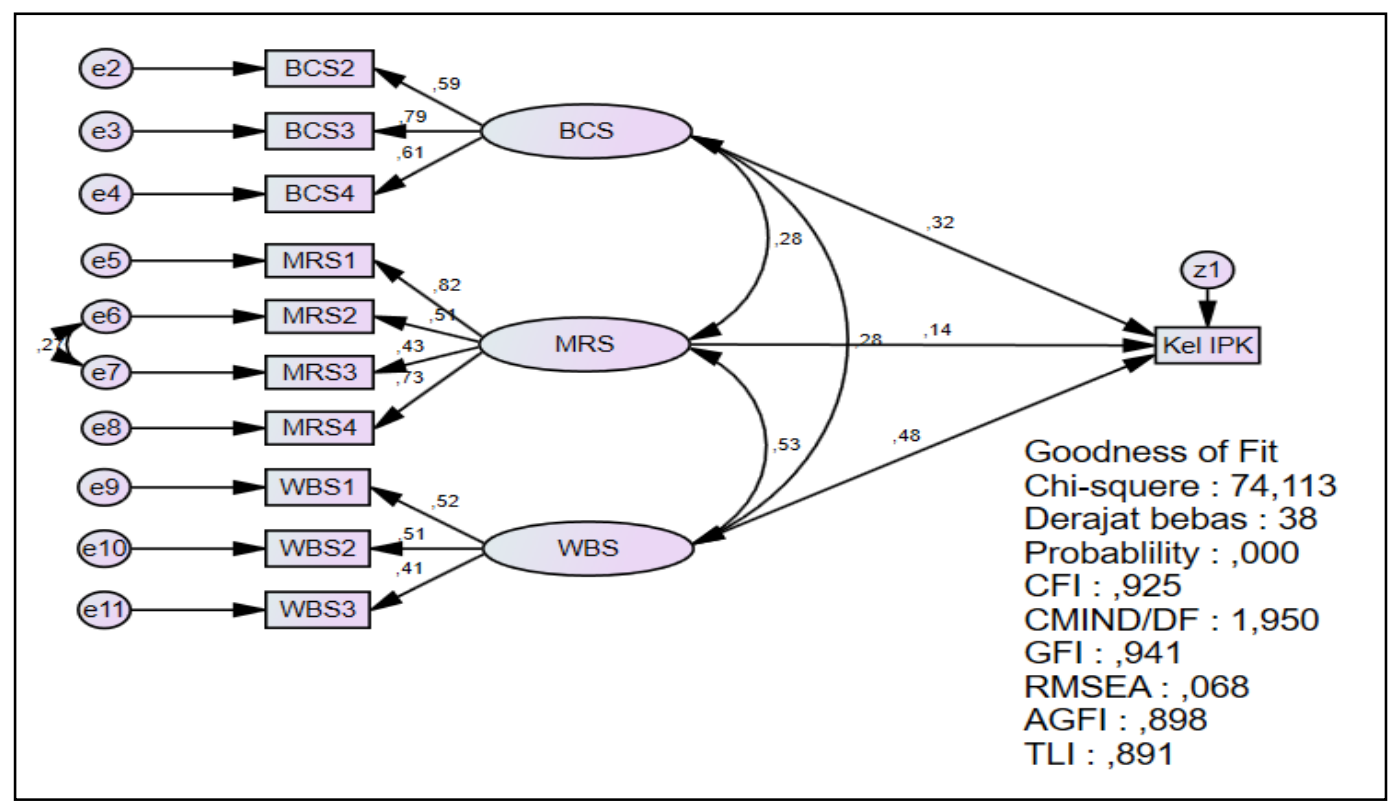

Sumber : data primer yang diolah

Gambar 1: Tahap Awal Struktural Equation Model

Model penelitian diuji tingkat kesesuaiannya dengan menggunakan berbagai kriteria goodness of fit dan menghasilkan index uji kelayakan yang dapat digambarkan dengan tabel dibawah ini :

Tabel 2: Index uji kelayakan model SEM Awal

\begin{tabular}{llll}
\hline \multicolumn{1}{c}{ Goodness of fit index } & \multicolumn{1}{c}{ Cut-off value } & Hasil Analisis & \multicolumn{1}{c}{ Evaluasi } \\
\hline$X^{2}$-Chi-squere & Diharapkan kecil & 74,113 & Belum Layak \\
Sign Probablility & 0,05 & 0,000 & Belum Layak \\
CMIN/DF & 2.00 & 1,950 & Layak \\
GFI & 0.90 & 0,941 & Layak \\
AGFI & 0.90 & 0,898 & Belum Layak \\
$T L I$ & 0.95 & 0,891 & Belum Layak \\
CFI & 0.95 & 0,925 & Belum Layak \\
RMSA & 0.08 & 0,068 & Layak \\
\hline
\end{tabular}

Berdasarkan hasil pengujian pada tabel 2 menunjukkan bahwa model belum cukup layak. Kemudian dilakukan modifikasi untuk memperbaiki model sehingga valid untuk pembuktian hipotesis berdasarkan petunjuk modification indices. 


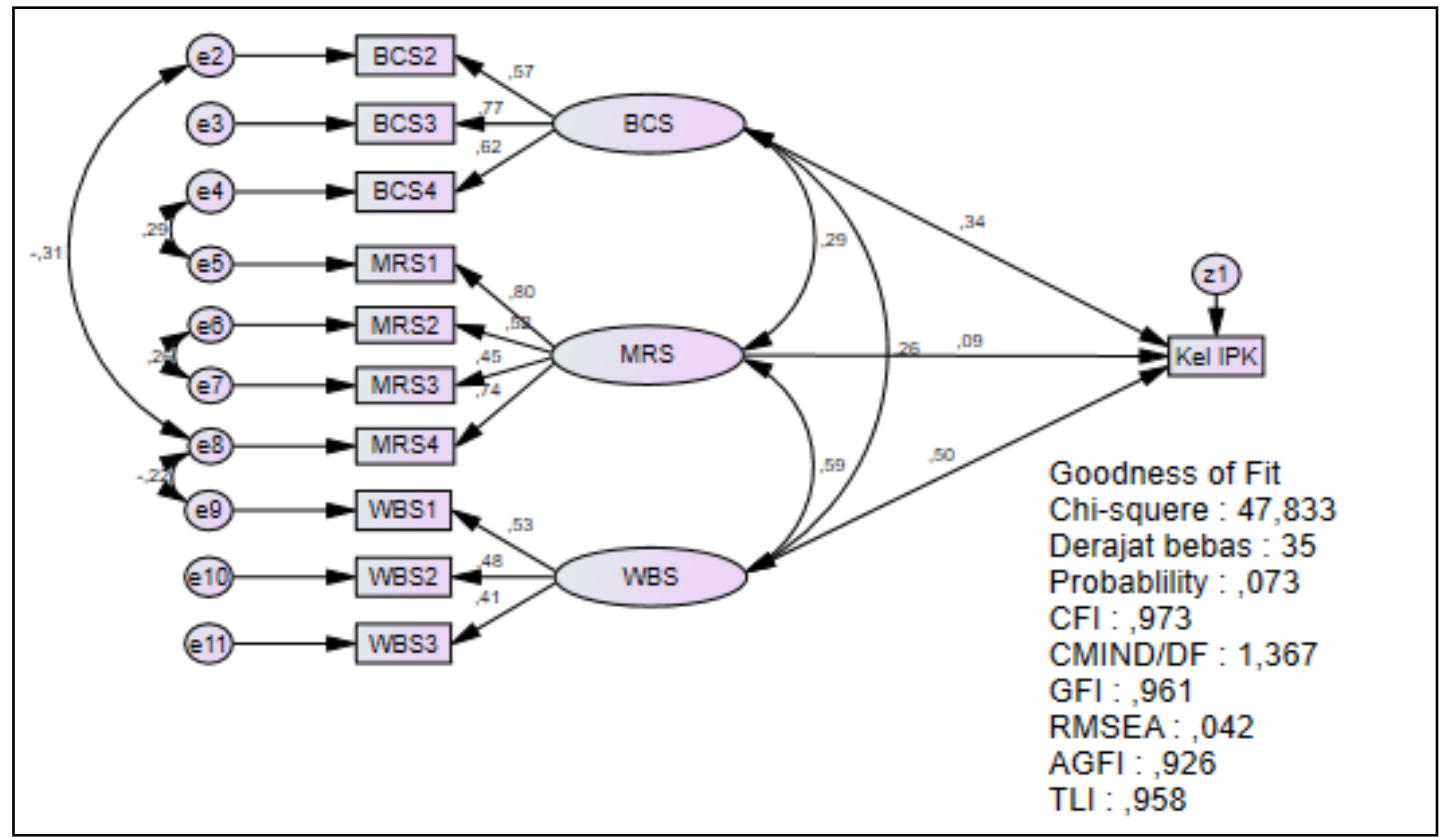

Sumber : data primer yang diolah

Gambar 2: Tahap Akhir Struktural Equation Model

Model penelitian yang sudah dimodifikasi kemnbali diuji tingkat kesesuaiannya dengan menggunakan berbagai kriteria goodness of fit dan menghasilkan index uji kelayakan yang dapat digambarkan dengan tabel dibawah ini

Tabel 3: Index uji Kelayakan SEM Tahap Akhir

\begin{tabular}{llll}
\hline Goodness of Fit Index & Cut-off Value & Hasil Analisis & Evaluasi \\
\hline$X^{2}$-Chi-squere & Diharapkan kecil & 47,883 & Layak \\
Sign Probablility & 0,05 & 0,073 & Layak \\
CMIN/DF & 2.00 & 1,367 & Layak \\
GFI & 0.90 & 0,961 & Layak \\
AGFI & 0.90 & 0,926 & Layak \\
TLI & 0.95 & 0,958 & Layak \\
CFI & 0.95 & 0,973 & Layak \\
RMSA & 0.08 & 0,042 & Layak \\
\hline
\end{tabular}

Berbagai kriteria sudah tidak terdapat pelanggaran kritis berdasarkan evaluasi model yang diajukan bahwa evaluasi model terhadap konstruk secara menyeluruh sehingga dapat dikatakan model dapat diterima.

Tabel 4: Tahap Akhir Index uji kelayakan SEM

\begin{tabular}{lcccccc}
\hline & & & Estimate & S.E. & C.R. & P \\
\hline KelIPK & $<---$ & BCS &, 590 &, 151 & 3,898 & $* * *$ \\
KelIPK & $<---$ & MRS &, 113 &, 156 &, 719 &, 472 \\
KelIPK & $<---$ & WBS & 1,112 &, 399 & 2,786 &, 005 \\
& & & & & & \\
\hline
\end{tabular}

Hasil uji hipotesis dari penelitian ini adalah: 
1) Basic Computer Skills berpengaruh positif terhadap prestasi akademik. Parameter estimasi untuk pengujian pengaruh Basic Computer Skills terhadap prestasi akademik mahasiswa (IPK) menunjukan nilai CR 3,898 dengan probabilitas sebesar 0,000. Nilai CR lebih besar dari 1,96 dan probabilitas lebih kecil dari 0,05 yang menunjukkan penerimaan H1 memenuhi syarat. Dengan demikian disimpulkan hipotesis 1 dapat diterima dengan pernyataan Basic Computer Skills Berpengaruh signifikan dan positif terhadap Prestasi Akademik Mahasiswa (IPK).

2) Media Related Skills berpengaruh positif terhadap prestasi akademik. Parameter estimasi untuk pengujian pengaruh Media Related Skills terhadap prestasi akademik mahasiswa (IPK) menunjukan nilai CR 0,719 dengan probabilitas sebesar 0,472. Nilai CR lebih kecil dari 1,96 dan probabilitas lebih besar dari 0,05, yang menunjukkan penerimaan $\mathrm{H} 2$ tidak memenuhi syarat. Dengan demikian disimpulkan bahwa hipotesis 2 tidak dapat diterima, dengan kata lain Media Related Skills tidak berpengaruh signifikan terhadap prestasi akademik mahasiswa (IPK).

3) Web Based Skills berpengaruh positif terhadap prestasi akademik. Parameter estimasi untuk pengujian pengaruh Web Based Skills terhadap prestasi akademik mahasiswa (IPK) menunjukan nilai CR 2,786 dengan probabilitas sebesar 0,005. Nilai lebih besar dari 1,96 dan probabilitas yang lebih kecil dari 0,005 , yang menunjukkan penerimaan H3 memenuhi syarat. Dengan demikian disimpulkan bahwa hipotesis 3 dapat diterima, dengan pernyataan Web Based Skills berpengaruh signifikan dan positif terhadap prestasi akademik mahasiswa (IPK).

\section{KESIMPULAN}

Setelah dilakukan pengujian hipotesis penelitian dengan metode struktural equation modeling, maka didapatkan kesimpulan sebagai berikut :

1) Basic Computer Skills berpengaruh positif terhadap prestasi akademik. Parameter estimasi untuk pengujian pengaruh Basic Computer Skills terhadap prestasi akademik mahasiswa (IPK) menunjukan nilai CR 3,898 dengan probabilitas sebesar 0,000.

2) Media Related Skills tidak berpengaruh signifikan terhadap prestasi akademik. Parameter estimasi untuk pengujian pengaruh Media Related Skills terhadap prestasi akademik mahasiswa (IPK) menunjukan nilai CR 0,719 dengan probabilitas sebesar 0,472.

3) Web Based Skills berpengaruh positif terhadap prestasi akademik. Parameter estimasi untuk pengujian pengaruh Web Based Skills terhadap prestasi akademik mahasiswa (IPK) menunjukan nilai CR 2,786 dengan probabilitas sebesar 0,005.

\section{Referensi}

Adiputra, S., (2015), Keterkaitan Self Efficacy dan Self Esteem Terhadap Prestasi Belajar Mahasiswa. Jurnal Fokus Konseling 1(2). STKIP Muhammadiah Pringsewu Lampung: Lampung.

Agarwal, R., et al., (2000). Research Report: the Evolving Relationship between General and Specific Computer Self-Efficacy — an Empirical Assessment. Information Systems Research 11(4): 418-430. University of Maryland: Maryland. 
Compeau, Deborah R. And C.A. Higgins .(1995)., Computer Self Efficacy: Development of Measure and Initial Test, MIS Quartely, Vol. 19, No. 12: www.misq.org/archivst/vol/no19/issue2/vol19n2art4.html - 3k.

Ferdinand, Augusty. 2002. Structural Equation Modelling dalam Penelitian Manajemen. Semarang:FE UNDIP.

Hair, J.F, Black. W.C, Babin. J. B \& Anderson, R.E. 2010. Multivariate Data Analysis : A Global Perspective. Seventh Edition. Pearson Education International. Upper Saddle River: New Jersey.

Handayani, F. (2013), Hubungan Self Efficacy dengan Prestasi Belajar Siswa Akselerasi. Universitas Negeri Surabaya: Surabaya.

Rustiana, R. (2004). "COMPUTER SELF EFFICACY (CSE) MAHASISWA AKUNTANSI DALAM PENGGUNAAN TEKNOLOGI INFORMASI: TINJAUAN PERSPEKTIF GENDER." Jurnal Akuntansi dan Keuangan 6(1): pp. 29-39. Unika Seogijapranata : Jakarta

Teo, T. and J. Hwee Ling Koh, (2010), Assessing the Dimensionality of Computer Self-Efficacy among Pre-Service Teachers in Singapore: A Structural Equation Modeling Approach, International Journal of Education and Development using ICT 6(3): 718. : University of Macau: Macau.

Warsito, H., (2012), Hubungan antara Self-Efficacy dengan Penyesuaian Akademik dan Prestasi Akademik (Studi pada Mahasiswa FIP Universitas Negeri Surabaya), Pedagogi 9(1): 29-47. Universitas Negeri Surabaya: Surabaya. 